\section{Perceptive handbook}

Handbook of Perception. Volume 5: Seeing. Edited by Edward C. Carterette and Morton P. Friedman. Pp. xxii + 527. (Academic: New York and London, September 1975.) \$28.50; $£ 13.70$.

THis volume, the fourth to be published in a set of ten, could readily stand alone as an advanced textbook of visual perception. The contributors are well known, the text is uniformly clear and intelligent, and the level of presentation is more even than in earlier volumes. The organisation is conventional. Le Grand opens, with an informed history of visual science and an introduction to radiometry and photometry. In a distinguished chapter on receptive fields, J. Robson surveys the neurophysiology of the visual system and offers a shrewd discussion of the widely-canvassed idea that the visual cortex acts as an analyser of spatial frequencies. Colour vision is covered by $R$. and $K$. De Valois and by $\mathrm{R}$. Boynton; temporal factors by $\mathrm{L}$.

\section{(continued from previous page)}

Bronowski claims that the Renaissance study of ancient texts established standards of accuracy and exactness of inference which revealed new possibilities to science. Toulmin holds that humanism favoured a scepticism concerning human knowledge inimical to confident theorising about nature. The most fundamental disagreement, however, is that between Bronowski and Heiko Obermann. Bronowski writes, "Copernicus's attitude implies that the single truth exists in nature and as nature, and cannot be established or overturned by any authority other than the study of nature herself." Obermann does not deny that that was Copernicus's attitude; what he does deny is that it is right. "Astronomy," he asserts, "cannot reveal the 'true causes' of astral phenomena insofar as final causality lies beyond its purview." Again, "the goal of the natural sciences is validity in the sense of accuracy, whereas that of the humanities, particularly of philosophy and theology, is validity in the sense of truth." How philosophy and theology are to reveal the true causes of astral phenomena, Obermann does not proceed to explain.

The historical papers I have mentioned are interesting, as are some that I have not found room for; unfortunately they are outweighed by a mass of material which is of very limited interest.
Ganz; spatial resolution and interaction by J. Thomas; the perception of patterns and objects by Dodwell; depth perception by W. Richards; and the perception of movement by $\mathrm{R}$. Sekuler. In a final chapter on Vision and Art, M. Pirenne discusses the difference between viewing a painting and viewing a trompe l'oeil. Although the chapter headings are classical the fresh concepts of the seventies have a firm place in the text. If there are no traces of the grand schools that once dominated textbooks of perception and if most of the debates are now at a technical level, then that may be wholesome enough. Dodwell indeed argues here that the need for all-embracing theory of visual perception has passed and that the many different processes necessary for perception must be considered individually and in detail.

What the book lacks is an Editor and its weakness lies in the same absence of coordination that marked earlier volumes: there is clear internal evidence that the contributors have not read each other's chapters and indeed there is grave doubt as to whether anyone with editorial authority has read the entire text. Thus the concepts of Fourier Analysis are independently introduced by Robson, by Ganz and by Thomas, when what was needed was one separate account written by a single hand. It is extraordinary, even outrageous, that Boynton and De Valois have not been invited, or have not been pressed, to read each other's excellent chapters on colour vision. Both chapters, for example, discuss the colour-naming work of Boynton and the attempt by De Valois to relate Boynton's results to the electrophysiology of the primate; each refers to earlier papers by the other but there are no cross-references between the two chapters. When cross-references do occur they are often blind: thus Le Grand writes "Chemical structure of rhodopsin and of other visual pigments will be discussed by Robson, in Chapter 4 of this volume", but the reader will turn to Chapter 4 in vain. J. D. Mollon

\section{Subunit interactions in enzymes}

Subunit Enzymes: Biochemistry and Functions. (Enzymology: A Series of Textbooks and Monographs.) Edited by Kurt E. Ebner. Pp. $x+332$. (Dekker: New York, August 1975.) \$24.50.

THE aim of this book is to examine by means of representative examples the different types of subunit interactions that may exist in proteins. The proteins chosen for detailed consideration are glutamine synthetase of Escherichia coli, UDP-galactose-4-epimerase, lactose synthetase, acetyl coenzyme A carboxylases, tryptophan synthetase, and the steroid carrier protein. Each is the subject of a chapter written by research workers who have made major contributions to the field. An introductory chapter, on the general structure and thermodynamics of multisubunit proteins and molecular models for cooperativity, also contains sections on haemoglobin, CTP synthetase and glyceraldehyde-3-phosphate dehydrogenases, but these are not sufficiently detailed nor up-to-date to be of value. Most of the other chapters are clear and comprehensive accounts of the relationship between structure and function, with emphasis on the significance of the multisubunit structures; some include unpublished work and addenda containing recently published findings.

The acetyl coenzyme A carboxylases of $E$. coli and avian liver are described in an excellent article by Lane, Polakis and Moss. These are examples of protomers composed of several different polypeptide chains which catalyse distinct partial reactions or, in the case of the animal enzyme, combine with the allosteric activator citrate and induce association of the protomer to form the active linear polymer. Tryptophan synthetase (Crawford) has an $\alpha_{2} \beta_{2}$ structure, and the two types of polypeptide chain again catalyse separate partial reactions; in the protomer their catalytic efficiency is increased and dissociation of the indole intermediate is prevented. Glutamine synthetase is subject to covalent modification by an elaborate enzyme cascade system, regulated by metabolites, and in the article by Ginsberg and Stadtman the interactions between adenylylation, essential divalent cations and allosteric effectors are discussed in detail. Less is known about interactions between the two subunits in the UDP galactose epimerase molecule, which contains a single $\mathrm{NAD}^{+}$molecule acting unusually as a prosthetic group rather than a coenzyme (Gabriel, Kalckar and Darrow). The function of $\alpha$ lactalbumin as a modifier protein that decreases the $K_{\mathrm{m}}$ of galactosyl transferase for glucose as acceptor, and its possible role in the control of lactose synthesis in the mammary gland, is discussed by Ebner and Magee. The squalene and sterol carrier protein is needed for maximal activity of several enzymes involved in cholesterol and bile acid and synthesis, and its probable function as a lipid-carrier in these pathways is described by Dempsey.

This book serves a useful purpose in bringing together diverse examples of subunit interactions in enzymes. The omission of aspartate transcarbamylase is surprising. 